\title{
Nöromusküler Hastalıklarda Solunum Fonksiyonlarının Değerlendirilmesi: Derleme
}

\section{Assessment of Ventilatory Function in Patients with Neuromuscular Disease: Review}

\section{Dr. Ipek YELDAN $N^{I}$, Dr. Gökşen KURAN}

ASLAN ${ }^{1}$

${ }^{1}$ Istanbul Üniversitesi
Sağlık Bilimleri Fakültesi
Fizyoterapi ve
Rehabilitasyon Bölümü,
Nörolojik Fizyoterapi ve
Rehabilitasyon Anabilim
Dalı

Yazışma adresi/

Coresspondence İpek Yeldan, İstanbul Üniversitesi Sağllk Bilimleri Fakültesi Fizyoterapi ve Rehabilitasyon Bölümü, Nörolojik Fizyoterapi ve Rehabilitasyon Anabilim Dalı Demirkapı Caddesi, Karabal Sokak, Bakurköy/İstanbul, ipekyeldan@gmail.com

Geliş Tarihi/Recevied 26/06/2014

Kabul Tarihi/Accepted 06/08/2014

HSP 2014 1(2): 127-136

\section{Özet}

Nöromusküler hastalıklarda kas iskelet sistemi problemlerinin yanı sıra solunum kas zayıflığı ve buna bağlı olarak solunum disfonksiyonu gelişebilmektedir. Solunumsal komplikasyonlar, özellikle kronik ve hızlı ilerleyen nöromusküler hastalıklarda, morbidite ve mortalitenin en önemli nedenlerindendir. Bu hastalarda vital kapasite azalır, restriktif solunum paterni görülür. Solunum kas zayıflığı nedeniyle, nöromusküler hastalığı olan kişilerde yorgunluk, nefes darlığı, sekresyon birikimi, tekrarlayan alt solunum yolu infeksiyonları, solunum yetmezliği, pulmoner hipertansiyon ve akut veya kronik korpulmonale gelişebilir. Uyku ile ilişkili solunumsal problemler de başlangıçta uyku sırasında görülürken hastalığın ilerlemesiyle birlikte uyanıklık dönemine de yansır. Nöromusküler hastalıklarda sistematik klinik değerlendirme, erken dönemde hastanın fiziksel kapasitesindeki yetersizlik nedeniyle maskelenen solunumsal semptom ve bulguların saptanmasında esastır. $\mathrm{Bu}$ derleme nöromusküler hastalıklarda karşılaşılan solunum problemleri ile anamnez, fizik muayene, solunum kas gücü ölçümleri, arter kan gazları analizi, tepe öksürük akımı ölçümü, radyolojik değerlendirme, spirometrik ölçümler ve uyku başlıkları altında değerlendirmeyi kapsamlı olarak gözden geçirecektir.

Anahtar Kelimeler: Nöromusküler hastalıklar, solunum, solunumsal değerlendirme

\begin{abstract}
Respiratory muscle weakness and consequently respiratory dysfunction may occur as well as musculoskeletal problems in patients with neuromuscular diseases. Respiratory complications are the most important cause of morbidity and mortality particularly in chronic and rapidly progressive neuromuscular diseases. Vital capacity is reduced and a restrictive ventilatory pattern is seen in these patients. Due to respiratory muscle weakness; fatigue, breathlessness, secretion retention, recurrent lower respiratory tract infections, respiratory failure, pulmonary hypertension, and acute or chronic corpulmonale may occur in patients with neuromuscular diseases. While respiratory problems may manifest initially during sleep, it also reflect to awake period with progression of diseases. Systematic clinical evaluation of neuromuscular diseases is essential for the detection of respiratory signs and symptoms which are masked because of physical capacity inability of patients in early stage. This review will evaluate comprehensively the assessment of respiratory problems which are encountered in neuromuscular diseases under the headings of history, physical examination, respiratory muscle strength measurements, arterial blood gas analysis, peak cough flow measurements, radiologic evaluation, spirometry and sleep.

Key Words: Neuromuscular diseases, respiration, respiratory assessment
\end{abstract}




\section{Giriş}

Nöromusküler hastalıklar iskelet kasının ilerleyici, herediter, dejeneratif hastalıklarıdır. Nöromusküler hastalığı olan kişilerde hastalığın tipine göre seyir değişmekle birlikte, genelde ilerleyici kas kuvvet kaybı, atrofi, kontraktür, deformiteler ve ilerleyici yetersizlik sözkonusudur. ${ }^{1-3}$ Nöromusküler hastalıklar kas iskelet sistemi problemlerinin yanı sira yutma bozuklukları, solunum kas zayıflığı ve buna bağlı olarak gelişen solunum yetmezliğine yol açan bir grup hastalığ1 içerir. Nöromusküler hastalıkların çoğu yürüme kaybı, tekerlekli sandalyeye bağlanma, omurga deformiteleri, yutma bozuklukları, solunum kas zayıflı̆̆ı ve buna bağlı olarak solunum yetmezliğine neden olurlar. Solunum yetmezliği, kronik ve hızlı ilerleyen nöromusküler hastalıklarda morbidite ve mortalitenin en sık görülen sebebidir. ${ }^{4-6}$ Solunumsal yetmezlik belirti ve bulguları hastanın mobilitesindeki sinırlanmalar nedeniyle maskelenebilir ve klinik tablo ciddileşene kadar belirgin olmayabilir (Tablo1). ${ }^{7}$ Nöromusküler hastalıkların değerlendirilmesinde solunum sistemin değerlendirilmesi problemlerin erken dönemde saptanması açısından önemlidir.

\section{Tablo 1. Solunum Yetmezliğinin Semptom Ve Bulguları}

\section{Semptomlar}

- Genel zayiflik

- Disfaji

- Disfoni

- İstirahatte ve eforda dispne

- Yorgunluk

- Uyku bozukluğu

\section{Klinik Bulgular}

- Hizlı yüzeyel solunum

- Taşikardi

- Zayif öksürük

- Kesik kesik konuşma

- Yardımeı solunum kası kullanımı

- Abdominal paradoksal hareket

- Ortopne

- Trapez ve boyun kaslarında zayıflık

- Yutma sonrası öksürük

\section{Laboratuar verileri}

- $\mathrm{VK} \leq 15 \mathrm{~mL} \cdot \mathrm{kg}^{-1}, \mathrm{VK} \leq 1 \mathrm{~L}$ veya stabil durumdakinden $\% 50$ azalma veya oturma pozisyonundan supin pozisyona geçerken $>\% 20$ düşme

- Maksimum inspiratuar basınç (MİP) $\leq 30 \quad \mathrm{cmH}_{2} \mathrm{O}$, maksimum ekspiratuar basınç $(\mathrm{MEP}) \leq 40$ $\mathrm{cmH}_{2} \mathrm{O}$

- Noktürnal desatürasyon

- $\mathrm{PaCO}_{2}>45 \mathrm{mmHg}$ 
Göğüs duvarı ve akciğer kompliyansının azalması sebebiyle, zayıflamış solunum kasları üzerine binen mekanik yük artar. Solunum kaslarına binen yük ve solunum kaslarının kapasitesi arasındaki dengesizlik, yorgunluğa ve bu hastalarda en önemli ölüm nedeni olabilen solunum yetersizliğine yol açabilir. Primer klinik tablo; hiperkapni, hipoksemi ve asidoz ile sonuçlanan hipoksidir. Uzun süreli klinik tablo hastalığa göre değişebilirse de, genellikle sekresyon birikimi, atelektazi ve alt havayolu infeksiyonlarını içerir. ${ }^{7,8}$

Nöromusküler hastalıklarda karşılaşılan başlıca problemlerden birisi, solunum kas fonksiyonunun ilerleyici bozukluğudur. Değerlendirmede özellikle akciğer ile akciğerlerin ventilasyonu için gerekli mekanik enerjiyi sağlayan solunum kaslarının değerlendirilmesi yer almalıdır. ${ }^{9,10}$

\section{Solunum patofizyolojisi}

Solunumu etkileyen tüm nöromusküler hastalıklar; inspirasyon volümünde, dolayısıyla total akciğer kapasitesinde (TAK) azalmaya neden oldukları için restriktif akciğer hastalıkları arasında yer alırlar. Gögüs kompliyansının yanısıra, maksimum inspirasyon ve ekspirasyon basınçları ve benzer şekilde çoğu akciğer volüm ve kapasiteleri azalmıştır. ${ }^{11}$ Gögüs duvarı kompliyansı kronik kas hastalığı olan kişilerde yaklaşık olarak \%30 azalır. Fonksiyonel rezidüel kapasite (FRK) değişmemiş, azalmış ya da hafifçe artmış olabilir. Kronik kas hastalığı olan kişilerde FRK'de orta derecede azalma ve normal rezidüel volüm (RV) ile ilişkili olan, vital kapasite (VK) ve TAK'de orta derecede azalma vardır. VK'de azalma, yalnızca solunum kas zayıflı̆̆ı sebebiyle değil, aynı zamanda akciğer ve göğüs duvarı kompliyansından da kaynaklanır. ${ }^{12}$ Düzenli olarak derin veya mekanik olarak yardımlı nefes alma olmaz ise maksimum nefes alma kapasitesi (MNAK) azalır, akciğer kompliyansı azalır ve hastada kronik mikroatelektaziler gelişir. Akciğerin ve gögüs duvarının azalmış elastisitesini aşmak için, solunumun artmış elastik işi gerekli hale gelir. Uzun vadede mikroatelektaziler, akciğer ve gögüs duvarı elastikiyetini bozar ve sonuçta göğüs kafesi hareketi sürekli olarak kaybolur. ${ }^{1,2,5}$

\section{Solunum kas disfonksiyonu}

Nöromusküler hastalıklarda solunum kas zayıflığ 1 sık karşılaşılan bir problemdir. Ancak hareket kayb1 nedeniyle genellikle geri planda kalır. Bu hastalarda solunum kas zayıflı̆̆ı, yetersiz ventilasyon, noktürnal hipoventilasyon veya yetersiz öksürük nedeni olabilir (Tablo 2). ${ }^{2,7,8,13}$ Ciddi solunum kas zayıflığı gelişen nöromusküler hastalığı olan kişilerde yorgunluk, nefes darlığı, sekresyonların bozulmuş kontrolü, tekrarlayan alt solunum yolu infeksiyonu, solunum yetersizliği, pulmoner hipertansiyon ve akut veya kronik korpulmonale gelişebilir. ${ }^{14}$

Kronik nöromusküler hastalık sebebiyle ciddi solunum kas zayıflığı olan hastaların fiziksel aktiviteleri kısıtlı olduğu için nadiren solunum sistemlerine yük bindirirler ve bu nedenle de çoğu nefes darlığından şikayet etmez. ${ }^{15}$

Nöromusküler hastalıklarda görülen yetersiz ventilasyonun esas nedeni inspiratuar kas zayıflığıdır. İnspiratuar kasların zayıflığı tidal volümün azalmasına neden olur. Tidal volümü (TV) arttırmak ve alveoler ventilasyonun devamı için solunum hızı artar. Buna rağmen TV daha da azalabilir, alveolar hipoventilasyon ve arteriel karbondioksit basincinda artma meydana gelir. İnspiratuar kasların zayıflığı restriktif solunum paternine neden olur. İnspiratuar kas zayıflığı olan hastalar yardımcı solunum kaslarını kullanırlar ve diyafragmatik harekete yardımcı olabilmek için 
yerçekiminden yararlanırlar. Bunların sonucunda ortopne, yardımcı solunum kası kullanımı ve abdominal paradoks hareket gelişir., ${ }^{9,10}$ Yetersiz ventilasyona sıklıkla eşlik eden hipoksemi birçok nedene bağlıdır. Yetersiz ventilasyon tek başına hipoksemiye neden olabilir. İnspiratuar kas zayıflığ olan hastaların solunumu yüzeyeldir ve inspirasyonu etkin yapamazlar. Bu nedenle atelektazi gelişir bu da solunum sistemi kompliyansının azalmasına neden olarak, solunum işinin artmasına ve solunum kas yorgunluğuna yol açar. ${ }^{11,12}$

Ekspiratuar kas zayıflığı, kas hastalığı olan kişilerde yaygın olarak gözlenir. Etkisiz öksürüğe ve dolayısıyla sekresyonların atılımının bozulmasına sebep olur. Bu durum bazı hastalarda tekrarlayan alt solunum yolu infeksiyonlarına yol açabilir. Sağlıklı kişilerde, ekspiratuar kasların kuvvetli kasılması ile plevral basınçta oluşturulan büyük değişikliklerle merkezi intratorasik havayollarının dinamik kompresyonu, sekresyonların atılabilecekleri proksimale doğru hareket etmelerinde rol oynar. Ekspiratuar kas zayıflığı arttıkça, öksürme eforu sırasında oluşturulan plevral basınçlar azalır ve havayolu temizlenmesi bozulur. ${ }^{16,17}$

İnspirasyon ve ekspirasyon sırasında ağı basınçlarındaki azalma genel kas gücü değerlendirmesi ile ilişkili değildir. Hem nöromusküler hastalığın tipi hem de genel kas zayıflığının dağılımı solunum kas bozukluğu ile ilişkilidir. Proksimal ekstremite tutulumu olanların distal ekstremite kas zayıflığı olanlara göre anlamlı solunum kas zayıflı̆̆ 1 olma ihtimali vardır. ${ }^{18}$

Solunum kas zayıflığı olan hastalarda bulunan hızlı, yüzeyel solunum paterni solunum kas kuvvetindeki azalma nedeniyle olabileceği gibi, akciğer ve göğüs duvarı elastik rekoilindeki değişiklikler nedeniyle de olabilir. İnspiratuar kas tonusunda azalma, akciğer volümünü azaltan ve göğüs duvarı tonusunda ve uzayabilirliğinde kronik değişiklikler yaratan akciğer elastik rekoiline karşı koyamamaya yol açabilir. İnspiratuar kas gücünün \%30’u kaybolduğunda, gaz değişiminde anormallikler ortaya çıkabilir. ${ }^{19}$

\section{Tablo 2. Solunum Kas Zayıflığı Ile Ilişkili Problemler}

\begin{tabular}{|c|c|c|c|c|}
\hline & $\begin{array}{l}\text { Yetersiz } \\
\text { ventilasyon }\end{array}$ & Hipoksemi & $\begin{array}{l}\text { Yetersiz } \\
\text { öksürük }\end{array}$ & $\begin{array}{l}\text { Aspirasyon } \\
\text { riski }\end{array}$ \\
\hline İnspiratuar kas zayıflığ1 & $\mathrm{X}$ & $\mathrm{X}$ & $\mathrm{X}$ & \\
\hline Ekspiratuar kas zayıflığ 1 & & & $X$ & \\
\hline $\begin{array}{l}\text { Üst solunum yolu kas } \\
\text { zayıflığ } 1\end{array}$ & & & $X$ & $X$ \\
\hline
\end{tabular}

Solunum kas zayıflığına bağlı olarak öksürük mekanizmasının bozulması sonucu yetersiz hava yolu temizliği, tekrarlayan solunum yolu infeksiyonlarına, atelektazilere ve sonuç olarak solunum yetmezliğine sebep olabilir. $^{20}$

Konuşma, yutma ve sekresyonların temizlenmesinde rol oynayan bulber kasların zayıflığında bu fonksiyonlar etkilenir, aspirasyon riski artar, öksürük kuvveti azalır, sık tekrarlayan alt solunum yolu infeksiyonları oluşur. Salya, ağır yutma bozukluğunun bir göstergesidir., ${ }^{4,21}$ 


\section{Uyku ile ilişkili solunum bozuklukları}

Nöromüsküler hastalığı olan kişilerde uyku sırasında solunum sıklıkla anormaldir. Özellikle uykunun hızlı göz hareketleri (Rapid eye movements (REM)) döneminde interkostal ve yardımcı kasların aktivitesi azaldığı için üst hava yolu obstrüksiyonu görülür. Üst hava yolu obstrüksiyonu noktürnal hipoventilasyonu tetikleyebilir veya arttırabilir. Hızlı göz hareketi (REM) döneminde bozulmuş uyku kalitesi ile birlikte hipopne ve hiperkapni sıktır. Noktürnal desatürasyonun nedeni hipoventilasyondur. Oksijen desatürasyonun derecesi diyafragmatik disfonksiyonun ciddiyeti ile ilişkilidir. ${ }^{22}$

REM uykusu sırasındaki hızlı ve yüzeyel solunum paterni, hiperkapni ve kötüleşmiş oksijenasyona yol açan artmış ölü-boşluk vertilasyonuna neden olur. Solunum dürtüsünde azalma uyku sırasında belirginleşir. ${ }^{23}$

Paradoksal abdominal hareketi olan hastalarda, diyafragmanın solunuma katılımında anlamlı azalma ve dolayısıyla hem REM hem de non-REM uykusunda daha büyük oksijen desatürasyonu ortaya çıkar. Restriktif hastalıkta kan gazlarında ilk anlamlı bozukluk, REM uykusu sırasındaki hiperkapni ve hipoksidir. Uyanıkken hiperkapni VK beklenenin \%40’ının altına düştüğü zaman ortaya çıkar. Uyanıkken $\mathrm{CO}_{2}$ seviyesi 50 mmHg'yı aştı̆̆ında, noktürnal oksihemoglobin desatürasyonları ciddi olabilir. $^{24}$

Solunumsal problemler başlangıçta uyku sırasında görülürken hastalığın ilerlemesiyle birlikte uyanıklık dönemine de yansır. Noktürnal hipoventilasyon semptom ve bulguları uykusuzluk, kabus görme, sabah baş ağrısı, gün boyu uyuklama, yorgunluk, bilişsel fonksiyonlarda yavaşlamadır. ${ }^{25}$

\section{Nöromusküler Hastalıklarda Solunum Fonksiyonlarının Değerlendirilmesi}

Nöromusküler hastalıklarda sistematik klinik değerlendirme, erken dönemde hastanın fiziksel kapasitesindeki yetersizlik nedeniyle maskelenen solunumsal semptom ve bulguların saptanmasında esastir.

\section{Anamnez}

Solunum kaslarının fonksiyon bozukluğuna bağlı klinik tablo, etkilenen kas veya kas gruplarına ve disfonksiyonun derecesine bağlıdır. Dispne ve tekrarlayan alt solunum yolu infeksiyonları ile birlikte olan veya olmayan öksürük nöromusküler hastalık varlığının ilk klinik ipuçları olabilir. ${ }^{26}$

\section{Fizik muayene}

Solunum problemi klinik açıdan belirgin olan hastalarda sıklıkla istirahatte takipne görülür. Hem oturur hem de sırtüstü pozisyonda solunum kas kontraksiyonunun paterni araştırılmalıdır. Solunum hızı kaydedilmelidir. Global alveolar hipoventilasyon semptomlarının varlığı araştırılmalıdır. Nazal kanatlaşma, interkostal kas retraksiyonu, stenokleidomostoid ve skalen kasların kontraksiyonu değerlendirilmelidir. Göğüs kafesi ve abdomenin içeri paradoksal hareketi, solunum işyükünün, solunum kas gücünden daha büyük olduğunun ya da ciddi diyafram zayıflığının göstergesidir. ${ }^{8,9}$ Ciddi diyafram zayıflığında, üst göğüs kafesi dışarı doğru hareket ederken, üst abdomen içeri doğru hareket eder. Solunum hızında belirgin artma, ilerleyici yardımcı kas kullanımı ve ortopne görülür. ${ }^{13,14}$ 


\section{Radyolojik değerlendirme}

Göğüs radyografisinde sıklıkla diyafragmaların elevasyonuna bağlı olarak akciğer volümleri azalmıştır. $^{14}$

\section{Arter kan gazları analizi}

Arter kan gazları analizi asit-baz dengesinin ve alveolar ventilasyon yeterliliğinin değerlendirilmesinde altın standarttır. Arteriyel kan gazları bozuklukları yalnızca ciddi solunum kas zayıflığı olan hastalarda görülür. Hipoksemi genellikle hafiftir. İntrapulmoner şant, ventilasyon/perfüzyon dengesizliği ve mikroatelektazilere bağlı olarak gelişir. Öksürük refleksinde bozulma nedeniyle sekresyonların birikimi hipoksemi yaratabilir. Arteriyel oksihemoglobin ölçümü ile değerlendirilir. Hiperkarbi solunum kas gücünün duyarsız bir ölçümüdür. $\mathrm{PaCO}_{2}$ solunum kas gücü $\% 50$ den fazla azalmadıcça artmaz. Bikarbonat ve $\mathrm{pH}$ değerleri akut ya da kronik asidozis olup olmadığını belirlemeye yardım eder. ${ }^{27}$

\section{Solunum kas gücü ölçümü}

a) Maksimal ağız basıç̧ları

Kapalı havayoluna karşı istemli kontraksiyonla havayolu açılmasında ölçülen maksimal inspiratuar (MİP) ve ekspiratuar (MEP) ağız basınçları, solunum kas gücünü test etmede en kolay ve en yaygın olarak kullanılan yöntemlerdir. Black ve Hyatt' $1 n^{28}$ tekniği en sık kullanılandır. MïP, inspiratuar kas kuvvetini gösterir, derin ekspirasyondan sonra, RV'ye yakın ölçüdür. Maksimum ekspirasyon sonras1 sistem bir kapak ile kapatılır ve kişinin kapalı kapağa karşı en az 1.5 sn süren maksimal inspirasyon yapması istenir. Klinik uygulamada $-80 \mathrm{~cm} \mathrm{H} \mathrm{H}_{2} \mathrm{O}$ 'ya $(-8 \mathrm{kPa})$ erişemeyen MİP değeri anormal olarak kabul edilmektedir. MIP<-20/-30 $\mathrm{cm} \mathrm{H}_{2} \mathrm{O}$ olması solunum desteğine ihtiyaç olduğunu gösterir. ${ }^{29}$

MEP, ekspiratuar kas kuvvetini yansıtır. MEP, TAK'de ya da yakınında ölçülür. Maksimum inspirasyon sonrası sistem bir kapak aracılığıyla kapatılır ve kişinin kapalı sisteme karşı en az 1.5 sn süren maksimum ekspirasyon yapması istenir. Pulmoner sekresyonları temizleyecek etkili bir öksürük için MEP $>40 \mathrm{~cm} \mathrm{H}_{2} \mathrm{O}$ olmalıdır. ${ }^{30}$

$\begin{array}{llrlr}60 \text { erkekte yaş 20-54 } & \text { MİP } & 124 \pm 22 \mathrm{cmH}_{2} \mathrm{O} & \text { MEP } & 233 \pm 42 \mathrm{cmH}_{2} \mathrm{O} \\ 60 \text { kadında yaş 20-54 } & \text { MIP } & 87 \pm 16 \mathrm{cmH}_{2} \mathrm{O} & \text { MEP } & 152 \pm 27 \mathrm{cmH}_{2} \mathrm{O}\end{array}$

b) Nazal inspiratuar basınç

Nazal inspiratuar basınç, dönüştürücüye bağlı kateter yardımıyla ölçülür. Kateter burnun bir tarafına yerleştirilir. Oturur pozisyonda ölçüm yapılır. Normal bir ekspirasyon sonrası koklama manevrası yapılır. Genellikle 5-10 koklama manevrası sonrası bir platoya erişilir. Kişinin kooperasyonuna bağlıdır. Nazal inspiratuar basıncın $<70 \mathrm{cmH}_{2} \mathrm{O}$ olması diyafram kası zayıflı̆̆ının bir bulgusudur. İnspiratuar kas kuvvetinin noninvaziv bir yöntemle iyi ölçülmesini sağlar. ${ }^{31}$

c. Gögüs kafesi ve abdominal hareketin analizi

Normal tidal solunum sirasında, diyafram kontraksiyonunun plevral basincı azaltması ve abdominal basıncı arttırmasıyla, gögüs ve abdominal kompartmanlar senkronize olarak dışa doğru hareket ederler. $^{14}$ 
d. Transdiyafragmatik basınç gücü ölçümü

Diyafram gücünün (Pdi) değerlendirilmesi, gastrik (Pga) ve endoözofajiyal (Pes) basınçların ölçümü ile yapilir. $^{31}$

$$
\text { Pdi }=[\mathrm{Pga}]-[\mathrm{Pes}]
$$

e) Frenik sinir stimülasyonu

Diyafram gücünün ölçümünde kritik nokta, istemli eforlar sırasında diyaframın sürekli olarak maksimal aktivasyonunu elde edebilme yeteneğidir. Elektrofrenik stimülasyon bunu elde etmek için kullanılan bir metoddur. Frenik sinir; boyunda krikoid kartilaj seviyesinde, sternokleidomastoid kasının posterior kenarına yakın bölgede en yüzeyel olduğu yerde uyarılır. Deneyim gerektirir, hastalar için konforlu olmayabilir. Klinik ortamda ulaşılması zordur. ${ }^{30,31}$

\section{Tepe öksürük akımı (TÖA)}

TÖA'nın normal değeri erişkinlerde $>360$ L/dk'dır. Peak flow metre (PEF metre) veya pnömotakograf ile ölçülebilmektedir. Nöromusküler hastalığı olan hastalarda PEF metre ile ölçülen TÖA ekspiratuar kas kuvveti ölçümü için daha iyi ve güvenilirdir. Tepe öksürük akımı (TÖA), öksürügün etkinliğinin belirlenmesinde önemli bir göstergedir. TÖA'nın 270 L/dk'nın altına düştüğü durumlarda yardımlı öksürük teknikleri önerilmelidir. TÖA $<160 \mathrm{~L} / \mathrm{dk}$ olması hava yolu temizliğinin sağlanamamasına neden olur. Trakeal aspirasyon gerekebilir. ${ }^{32-35}$

\section{Spirometre}

Nöromusküler hastalık sebebiyle solunum kas zayıflı̆̆ı, VK'de azalma ile spirometre testinde restriktif patern oluşturur. Nöromusküler hastalığı olan hastalarda FVC azalır. FEV 1 değeri FVC oranında azalır, $\mathrm{FEV}_{1} / \mathrm{FVC}$ oranı değişmez dolayısıyla restriktif patern görülür. ${ }^{1} \mathrm{VK}$ ölçümü otururken ve yarı yatar pozisyonda yapılmalıdır. Dik pozisyondan sı̈üstü pozisyona geçildiğinde, VK'de \%25' den fazla azalma olması, diyafram zayıflığının ve uyku ile ilişkili hipoventilasyonun göstergesidir. ${ }^{4} \mathrm{VK} \leq 10$ $\mathrm{ml} / \mathrm{kg}$ olması solunum yetersizliğinin habercisidir ve solunum desteğine ihtiyaç olduğunu gösterir. ${ }^{5}$ Nöromusküler hastalıklı kişilerde 1 saniyede zorlu ekspirasyon volümü $\left(\mathrm{FEV}_{1}\right)$ ve zorlu ekspirasyon akımı (FEF) 25-75 ya da FEF50 (orta ekspirasyon akım hızlarının) ölçümü normal belirlenmiş değerlerden sıklıkla daha büyüktür. ${ }^{36}$

\section{Akciğer volümleri}

Nöromusküler hastalığı olan kişilerde restriktif ventilasyon paterni görülür. S1klıkla rastlanan azalmış TAK ve normal ya da azalmış FRK'dir. TAK' ’n düşük oluşu inspiratuar kas zayıflığını gösterir. RV genellikle yükseltilmiştir ve ekspiratuar kas zayıflığının bulgusudur. Göğüs duvarı deformitesi varlığında FRK ve RV normal veya düşük olabilir. ${ }^{14}$

\section{Maksimum Nefes Alma Kapasitesi (MNAK)}

Maksimum nefes alma kapasitesi (MNAK), kapalı glottis ile tutulabilen ve daha sonra dişarı verilen havanın maksimum volümünün ölçümüdür. MNAK akciğer kompliyansının ve orofarinjiyal ve larinjiyal kaslarının gücünün fonksiyonudur. VK'de kayıp ile derin nefes alma güçlüğü ortaya çıkar. Nöromusküler hastalığı olan hastaların çoğunda VK azalsa da MNAK değeri yüksek olabilir. 
MNAK/VK farkı bulber kas kuvvetinin ölçümünde kullanılabilir. Manuel yardımlı öksürme sırasında yeterli tepe öksürük hızlarını elde etmek için en azından 500 ml'lik MNAK gereklidir. ${ }^{37}$

\section{Maksimal istemli ventilasyon (MiV)}

MIV, normal ekspiratuar akım hızının varlığında solunum kas dayanıklılığının bulgusudur. MIV değerleri solunum kas gücü ile ilişkilidir ve solunum kas zayıflığını araştırmada VK'den daha hassas bir ölçümdür. $\mathrm{Bu}$ değerin progresif olarak azalması bazı nöromusküler hastalıklarda kötü prognoz göstergesi olabilir. ${ }^{11}$

\section{Uyku Değerlendirmesi}

Nöromusküler hastalıklarda uykuda solunum bozukluklarının saptanması açısından uyku çalışmaları değerlendirmede yer almalıdır. Uyku-uyanıklık anomalileri veya noktürnal solunum yetmezliği bulgu ve semptomları görülen hastalarda gece boyu polisomnografi veya solunum poligrafisi önerilir. ${ }^{25}$

Nöromusküler hastalıklarda solunum fonksiyonlarının değerlendirilmesi, çok yönlü düşünmeyi ve klinik karar vermeyi gerektiren dinamik bir süreçtir. Hastanın rutin kontrollere düzenli olarak katılması, günlük yaşamındaki değişimleri izlemesi ve gözlemlerini sağlık profesyonelleriyle paylaşması cesaretlendirilmelidir. Bu süreçte nöromusküler hastalığı olan kişiye tıbbi bakım sağlayan ekibin koordinasyonu, değerlendirme ve tedavi planının daha etkin ve kapsamlı olmasında önemli role sahiptir.

\section{Kaynaklar}

1. Rochester DF, Esau SA. Assessment of ventilatory function in patients with neuromuscular disease. Clin Chest Med 1994;15(4):751-763.

2. Bertorini TE. Introduction: Evaluation of patients with Neuromuscular Disorders. In: Bertorini TE editors. Neuromuscular Disorders: Treatment and Management. 1st ed. Philadelphia: Saunders; 3-19; 2010.

3. LS Aboussouan. Mechanisms of exercise limitation and pulmonary rehabilitation for patients with neuromuscular disease. Chron Respir Dis 2009 6: 231.

4. Polkey MI, Lyall RA, Moxham J, Leigh PN. Respiratory aspects of neurological disease. J Neurol Neurosurg Psychiatry 1999;66:5-15.

5. Bourke SC. Respiratory involvement in neuromuscular disease. Clin Med 2014;14 (1):72-75.

6. Perrin C, Unterborn JN, Ambrosio CD, Hill NS. Pulmonary complications of chronic neuromuscular diseases and their management. Muscle Nerve 2004;29:5-27.

7. Ambrosino N, Carpene N, Gherardi M. Chronic respiratory care for neuromuscular diseases in adults. Eur Respir J 2009;34:444-451.

8. Dogan T, Kendirli MT, Togrol E. [Neuromuscular assessment of respiratory system function]. Solunum sistemi fonksiyonlarının nöromusküler degerlendirmesi. İcinde: [Functional assessment of respiratory system: Current approaches and clinical usage]. Solunum Sistemi Fonksiyonel Degerlendirmesi Güncel Yaklasımlar ve Klinikte Kullanımı. Ed. Kartaloglu Z, Okutan O. Birinci bask1, Deomed, İstanbul; 81-101, 2013. 
9. Kartaloğlu Z, Okutan O. [Current approach to respiratory problem in neuromuscular diseases]. Nöromusküler hastalıklardaki solunumsal problemlere güncel yaklaşım. Tuberk Toraks 2012;60(3):279-290.

10 Yeldan I. [Pulmonary rehabilitation in patients with neuromuscular diseases]. Nöromusküler hastalıklarda pulmoner rehabilitasyon. İçinde: Uzun M. editör. Kardiyak ve pulmoner rehabilitasyon. 1. Bask1. İstanbul Tip Kitabevi. 445-452,2014.

11. Criner GJ, Marchetti N. Effects of neuromuscular diseases on ventilation. In: Fishman AP, ed. Fishman's pulmonary diseases and disorders, vol 1.4th ed. New York: Mc Graw Hill; 1635-1665, 2008.

12. Racca F, Sorbo D, Mongini T, Vianello A, Ranieri VM. Respiratory management of acute respiratory failure in neuromuscular diseases. Minerva Anestesiol 2010;76:51-62.

13. Laghi F, Tobin MJ. Disorders of the respiratory muscles. State of the art. Am J Respir Crit Care Med 2003,168:10-48.

14. Cotes JE, Chinn DJ, Miller MR. Thoracic cage and respiratory muscles. Lung Function. $6^{\text {th }}$ Edition. Blackwell Publishing;99-110, 2006.

15. Matecki S, Petrof BJ.Hamilton. Physiologic basis of respiratory diseases. In: Hamid Q, Shannon J, Martin J, editors. Respiratory consequences of neuromuscular disease. BC Decker Inc, Hamilton, Ontario; 319-329; 2005.

16. Rodríguez-Roisin R, Roca J. Mechanisms of hypoxemia. Intensive Care Med 2005;31(8):1017.

17. Finder JD, Birnkrant D, Carl J, Farber HJ, Gozal D, Iannaccone ST et al. Respiratory Care of the Patient with Duchenne Muscular Dystrophy ATS Consensus Statement. Am J Respir Crit Care Med 2004; Vol 170. pp 456-465.

18. McCool FD. Global Physiology and Pathophysiology of Cough. ACCP Evidence-Based Clinical Practice Guidelines. Chest 2006;129;48-53.

19. Bach JR, Smith WH, Michaels J, Saporito L, Alba AS, Dayal R et al. Airway secretion clearance by mechanical exsufflation for post-poliomyelitis ventilator-assisted individuals. Arch Phys Med Rehabil 1993;74:170-177.

20. Vianello A. Neuromuscular Disorders. In: Palange P, Simonds A editors. ERS Handbook Respiratory Medicine. 1st edition. Latimer Trend\&Co.Ltd, UK; 361-364; 2010.

21. Hill M, Hughes T, Milford C. Treatment for swallowing difficulties (dysphagia) in chronic muscle disease. Cochrane Database Syst Rev 2004;2: CD004303.

22. Nicolle MW, Phil D. Sleep and Neuromuscular Disease. Semin Neurol 2009;29:429-437.

23. Oztura I, Guilleminault C. Neuromuscular disorders and sleep. Curr Neurol Neurosci Rep 2005;5(2):147-152.

24. Barbe F, Quera-Salva MA, McCann C, Gajdos P, Raphael JC, de Lattre J et. al. Sleep-related respiratory disturbances in patients with Duchenne Muscular Dystrophy. Eur Respir J 1994;7:14031408.

25. Bourke SC, Gibson GJ. Sleep and breathing in neuromuscular disease. Eur Respir J 2002;19:11941201.

26. American Thoracic Society /European Respiratory Society. Statement on respiratory muscle testing. Am J Respir Crit Care Med 2002; 166:518-624. 
27. Williams AJ. ABC of oxygen: assessing and interpreting arterial blood gases and acid-base balance. BMJ 1998;317(7167):1213.

28. Black LF, Hyatt RE. Maximal respiratory pressures: Normal values and relationship to age and sex. Am Rev Respir Dis 1969;99:696-702.

29. Martínez-Llorens J, Ausín P, Roig A, Balañá A, Admetlló M, Muñoz L, Gea J. Inspiratory Pressure: an Alternative for the Assessment of Inspiratory Muscle Strength? Arch Bronconeumol 2011;47(4):169-175.

30. American Thoracic Society/European Respiratory Society. Statement on respiratory muscle testing. Am J Respir Crit Care Med 2002;166:518-624.

31. Hughes PD, Polkey MI, Kyroussis D, Hamnegard CH, Moxham J, Green M. Measurement of sniff nasal and diaphragm twitch mouth pressure in patients. Thorax 1998;53:96-100.

32. Lawson RW. Neuromuscular Disorders. Critical Thinking in Respiratory Care. A Problem- Based Learning Approach. Eds. Mishoe SC, Welch MA JR.Mc Graw Hill Companies; p.577-609; 2002.

33. Sancho J, Servera E, Diaz J, Marin J. Comparison of peak cough flows measured by pneumotachograph and a portable peak flow meter. Am J Phys Med Rehabil 2004;83(8):608-612.

34. Leiner GC, Abramowitz S, Small MJ, Stenby VB. Cough peak flow rate. Am J Med Sci 1966;251(2):211-214.

35. Bott J, Blumenthal S, Buxton M, Ellum S, Falconer C, Garrod R, et al. Guidelines for the physiotherapy management of the adult, medical, spontaneously breathing patient. Thorax 2009; 64(Suppl I):i1-i51.

36. Sharma GD. Pulmonary Function Testing in Neuromuscular Disorders. Pediatrics 2009;123;219221.

37. Kang SW, Bach JR. Maximum insufflation capacity: the relationships with vital capacity and cough flows for patients with neuromuscular disease. Am J Phys Med Rehabil 2000; 79: 222-227. 